the statistical analysis and M. Ondrak and P. Schefter for technical assistance.

\section{Margarete Kalin} GERD KNERER

Department of Zoology,

University of Toronto,

Toronto, Canada

Received 14 January; accepted 12 April 1977.

1 Wilson, E. O. Sociobiology, (Harvard University Press, Cambridge, Massachusetts, 1975); The Insect Societies, (Harvard University Press, Cambridge, Massachusetts, 1971)

Knerer, G., \& Atwood, C. E. Science 179, 1090-1099 (1973).

3 Ghent, A. W. Behaviour 16, i 10-148 (1960).

Tostowaryk, W. Canad. Ent. 104, 61-69 (1972).

de Souza Dias, B. F. Studia Ent. 18, 401-432 (1975)

Carne, P. B. Proc. ecol. Soc. Austral. 1, 75-78 (1966).

Atwood, C. E. Symp. Genet. Biol. Italica, 10 250-260 (1962)

9 Grassé, P. P. Experientia 2, 77-82 (1946),

\section{Oestradiol and its biosynthesis in Phaseolus vulgaris $\mathrm{L}$.}

UNTIL recently the presence of steroidal oestrogens in plants has been a matter for debate ${ }^{1}$, and any physiological significance associated with them has been generally disregarded ${ }^{2,3}$. Although steroidal oestrogens have been found in extracts of a few species ${ }^{4}$, the identification of oestrone in Phaseolus was based on equivocal procedures ${ }^{5}$. Moreover, as with any compound present in low concentration, it is possible that at least some of the oestrogens identified in plant extracts are attributable to external contamination. This risk can be eliminated by demonstrating the incorporation of radioactive label from a known precursor into the compounds of interest. We report here the incorporation of radioactive isotopes from (3RS)-2 $-{ }^{14} \mathrm{C}$-mevalonic acid DBED (MVA), $4{ }^{14}{ }^{14} \mathrm{C}$-oestrone and potassium $6,7{ }^{3} \mathrm{H}$ oestrone sulphate into oestradiol by Phaseolus vulgaris L., cultivar Canadian Wonder. This represents the first case known to us of successful labelling of an identified steroidal oestrogen from ${ }^{14} \mathrm{C}-\mathrm{MVA}$ in a higher plant. It seems therefore that this class of mammalian sex hormone is produced in plants as well as animals.

Eight-day-old seedlings of $P$. vulgaris were sectioned under water at the base of the hypocotyl, stood in aqueous solutions of the various radioactive substances and allowed to transpire for $5 \mathrm{~d}$ (ref. 6). They were then planted in potting compost and grown for 2-5 weeks to facilitate normal growth and development. Harvested plants were solvent extracted (chloroform : methanol::2:1) under reflux in a Soxhlet apparatus for $8 \mathrm{~h}$. The extract was reduced to dryness in vacuo and taken up in ether. The phenolic fraction was isolated by partitioning with $1 \mathrm{~N}$ $\mathrm{NaOH}$, followed by acidification of the aqueous phase and repartitioning into ether. Thin-layer chromatography (TLC) and column chromatography on Sephadex LH-20 were used to isolate those fractions expected to contain oestrone $\left(E_{1}\right)$ and oestradiol $\left(\mathrm{E}_{2}\right)$.

The chromatographic mobilities of metabolites were compared with authentic compounds using TLC on three solvent systems (chloroform : methanol:: $95: 5$; benzene : propan2-ol :: 95:5; petroleum ether: ethyl acetate: : 75:25), column chromatography on LH-20 of the underivatised extracts and radio-gas-liquid chromatography (radio GLC) on OV-101 of the trimethylsilyl ether derivatives. Samples believed to contain oestradiol were diluted with non-radioactive carrier oestradiol and recrystallised to constant specific activity.

Using these techniques in combination, ${ }^{14} \mathrm{C}$ was observed to be incorporated into oestradiol from MVA and from $4-{ }^{14} \mathrm{C}$ oestrone. Similarly, oestradiol could be labelled from the
${ }^{3} \mathrm{H}$-oestrone sulphate. Attempts to label oestrone have not been conclusive; the rate of incorporation from radio-active MVA into the putative oestrone peak was much less than that observed for oestradiol.

One previous report describes the incorporation of ${ }^{14} \mathrm{C}$ MVA into a phenolic fraction by the higher plant Haplopappus heterophyllus, but the radioactive phenolic material did not correspond to any common steroidal oestrogen ${ }^{7}$. There have been many studies of the biotransformation of the mammalian steroid hormones progesterone and testosterone $e^{4,8}$, but our findings seem to represent the first report of a metabolic transformation of an oestrogen in plantsreduction of the 17 -keto steroid $\mathrm{E}_{1}$ to the $17 \beta$-hydroxyl compound $\mathrm{E}_{2}$.

Evidence of unlabelled oestradiol in extracts of seeds, vegetative and flowering plants was obtained using a modified radioimmunoassay (RIA) technique ${ }^{9}$ and combined gas chromatography-mass spectrometry (GC-MS). The GC-MS analysis ${ }^{10}$ involved continuous monitoring at the collector of the ion abundance at $\mathrm{m} / \mathrm{e} 416$ (molecular ion of the bis-trimethylsilyl derivative of oestradiol) as generated in the ion source from the GLC effluent of an SE-30 column operated at $250^{\circ} \mathrm{C}$. This process, commonly referred to as single-ion monitoring, enabled us to use the GS-MS system as a semi-specific detector for oestradiol.

This identification contrasts with the results of Kopcewicz $^{5}$ who presented TLC evidence for oestrone in $P$. vulgaris but could not detect oestradiol in the extracts. Indeed, this is only the second report of oestradiol detected as a plant steroid, Awad ${ }^{11}$ having isolated both oestrone and oestradiol from seeds of Prunus.

The verification of the endogenous biosynthesis of a steroid oestrogen in $P$. vulgaris opens the way to further studies of the suggested correlation between the quantitative levels of these compounds in this species and the onset of flowering. Preliminary data obtained by RIA suggest that oestradiol is present at $2-10 \mu \mathrm{g} \mathrm{kg}^{-1}$ fresh weight in seeds and leaves. It should also be possible to examine the overall pathway of biosynthesis of steroids in plants in order to investigate the presumed homology between plants and animals ${ }^{4}$. In addition, the potential for hormonal heterophylly $^{12}$ with respect to oestrogens in plants requires attention.

We thank Dr B. Cook for assistance with RIA and Professor K. Overton and J. Dalziel for radio-GLC facilities. The GC-MS instrumentation (AEI MS30) was provided by grants from the SRC, and I.J.Y. was financed by a postgraduate award from the SRC.

\section{J. Young \\ B. A. Knights \\ J. R. HillmaN}

Botany Department,

University of Glasgow,

Glasgow, UK

Received 9 March; accepted 15 April 1977.

1 Jacobsohn, G. M., Frey, M. S. \& Hochberg, R. B. Steroids 6, 93-99 (1965). Heslop-Harrison, J. in Plant Physiology, A Treatise (ed. Steward, F. C.) 6C, 133-271 (Academic, New York and London, 1972).

3 Zeevaart, J. A. D. A. Rev. Pl. Phys. 27, 321-348 (1976).

4 Heftmann, E. Phytochemistry 14, 891-901 (1975). 5 Kopcewicz, J. Phytochemistry 10, 1423-1427 (1971).

Bennett, R. O., Lieber, E. R. \& Heftmann, E. Pl. Physiol. 42, 973-976 (1967).

7 Bennett, R. O., Lieber, E. R. \& Heftmann, E. Pl. Physic

9 Dean, P. D. G., Exley, D. \& Goodwin, T. W. Phytochemistry 10, 2215-2216 (1971).

10 VandenHeuvel, W. J. A., Smith, J. L., Albers-Schönberg, G., Plazonnet, B. \& Bélanger, P., in Modern Methods of Steroid Analysis (ed. Heftmann, E.) 199-219 (Academic, New York, 1973 )

11 Awad, O. Phytochemistry 13,678-679 (1974)

12 Burdette, W. J. in Invertebrate Endocrinology and Hormonal Heterophylly (ed. Burdette, W. J.) 331-337 (Springer, Berlin, 1974). 